\title{
DIREITO À CIDADE E O IDEAL RACIONAL MODERNO
}

Gilson José Julião*

Resumo: $\mathrm{O}$ artigo tem o intuito de aprofundar, através de uma revisão bibliográfica, o tema do direito à cidade e o ideal racional moderno. O problema é a seguinte questão de que modo o direito à cidade se insere no ideal racional moderno? Para responder a esta questão, faremos uma análise exploratório-descritiva que terá o método quantitativo através de uma pesquisa teórica e também terá uma perspectiva de pesquisa histórica, já que será preciso abordar a trajetória e os fenômenos históricos relevantes para a formação de uma sociedade moderna baseada no ideal racional.

Palavras-chave: Direito; Cidade; Modernidade; Racionalidade.

\section{RIGHT TO THE CITY AND THE MODERN RATIONAL IDEAL}

Abstract: The article aims to deepen, through a bibliographic review, the theme of the right to the city and the modern rational ideal. The problem is the following question: how does the right to the city fit into the modern rational ideal? To answer this question, we will do an exploratory-descriptive analysis that will have the quantitative method through a theoretical research and will also have a perspective of historical research, since it will be necessary to address the historical trajectory and phenomena relevant to the formation of a modern society based on the rational ideal.

Keywords: Right; City; Modernity; Rationality.

\section{INTRODUÇÃO}

Este artigo tem o intuito de aprofundar, através de uma revisão bibliográfica, o tema do direito à cidade e o ideal racional moderno. O problema deste artigo tem como análise a possibilidade de responder a seguinte questão: de que modo o direito à cidade se insere no ideal racional moderno? Para responder a esta questão, faremos uma análise exploratóriodescritiva que terá o método quantitativo através de uma pesquisa teórica, pois será analisado

\footnotetext{
* Mestrando do PPGD/UNICAP. Especialista em Direito da Infância pela UFRPE. Graduado em Direito pela UNIFAVIP e em História pela UEPB. E-mail: gilsonjuliao10@gmail.com
} 
o conceito de direito à cidade elaborado por Henri Lefebvre e também terá uma perspectiva de pesquisa histórica, já que será preciso abordar a trajetória e os fenômenos históricos relevantes para a formação de uma sociedade moderna baseada no ideal racional.

Para isto, nosso artigo será dividido em quatros partes. No primeiro momento faremos uma contextualização histórica que será possível fazer uma abordagem das considerações sobre os antecedentes da modernidade, ou seja, o período pré-moderno que foi o cenário que possibilitou a construção do ideal racional moderno. Num segundo momento trataremos sobre os autores e as obras principais que utilizamos para a produção deste artigo, a exemplo de Anthony Giddens, em sua obra As Consequências da Modernidade; Boaventura de Sousa Santos, com o volume 1 do livro A crítica da razão indolente: contra o desperdício da experiência e David Harvey em Condição Pós-moderna, que teorizam o conceito do ideal racional moderno. Já na terceira e quarta parte deste trabalho será mostrado de que forma o direito à cidade é inserido neste projeto do ideal racional moderno, sendo que no primeiro momento será tratado sobre o surgimento das cidades e no segundo momento o direito à cidade como conceito surgido no ideal racional moderno.

\section{BREVES CONSIDERAÇÕES SOBRE OS ANTECEDENTES DA MODERNIDADE}

Como aponta Sandra Jatahy Pesavento, a "cidade é objeto de muitos discursos, a revelar saberes específicos ou modalidades sensíveis de leitura do urbano" (PESAVENTO, 2008, p. 80). Nossa proposta, neste estudo, parte do olhar histórico e jurídico sobre a produção do conhecimento e as formas pelas quais a cidade foi pensada e classificada enquanto um fenômeno urbano oriundo do ideal racional moderno.

Para iniciar a escrita sobre o assunto do ideal racional moderno é necessário tratar sobre as questões históricas para contextualizar e situar no tempo, no entanto, não faremos aqui uma abordagem histórica linear, mas cíclica, pois entendemos que a historicidade é feita de continuidades e rupturas. Deste modo, nesta primeira parte trataremos dos antecedentes da chamada modernidade que é o cenário que prepara o terreno para a modernidade que se encontra no palco histórico ocidental de enfraquecimento do pensamento que se consolida no medievo. Este período passa por: 


\begin{abstract}
Uma paisagem de escassos habitantes, de natureza geofísica insuscetível de ser governada, de esfacelamento político, de grave insegurança social, a qualificação primitiva indica pontualmente um mundo dominado pelo real, em que pobres formigas humanas - absolutamente incapazes de confiar nós próprios recursos individuais - procuram e encontram refúgio em uma incumbente natureza cósmica ou em micro-comunidades salvadoras. (GROSSI, 2007, p. 11)
\end{abstract}

É neste contexto que surge a modernidade, pois no medievo ou na dita idade medieval não existia um ente ou figura política que pudesse unificar ou centralizar uma concepção política que pode ser considerada um Estado. Como afirma Grossi (2007, p. 12), nem "monarquias, principados laicos e eclesiásticos, cidades livres, as mil manifestações feudais" merecem ser considerados Estados.

No senso comum e também no mundo acadêmico é corriqueira a conceituação do período medievo como a fase da chamada "trevas da religião", "mundo das trevas", marcada pela ignorância e obscuridade. Porém entendemos que esta conceituação tem um tempo histórico de construção, do ponto de vista historiográfico, errôneo e que foi formulado justamente no período moderno e da ideia de um ideal racional que tinha como foco romper com as estruturas ditas arcaicas da pré-modernidade. "O início do século XVII, o clima já era hostil às questões aristocráticas e religiosas, fomentou ainda mais a aversão à Idade Média" (FERRARA, 2018, p. 310). Deste modo se inicia um tempo de "luz" em contraposição às supostas trevas medieval.

O século XIV, no plano antropológico, mas também naquele político e social, é tempo de desconfiança, tríplice desconfiança: em relação aos velhos valores, em relação à velha ordem, em relação à dimensão comunitária em que o universo medieval tinha se construído; uma desconfiança marcada pela exigência de buscar novas estradas e de apostar em novos valores. (GROSSI, 2007, p. 20)

Portanto, é neste contexto que surge o ideal racional moderno.

\title{
3. O IDEAL RACIONAL MODERNO
}

O direito racionalista dos séculos XVII e XVIII parte da ideia da função de uma nova racionalidade moderna através do exercício da razão e da observação. Destaco aqui os três fundadores da racionalidade política moderna que são Hobbes, Locke e Rousseau, cada um, do seu modo, teorizaram concepções de racionalidade e do direito moderno passando e se 
opondo a fase da chamada "trevas" da religião e da tradição para o período da luz, do iluminismo que é o embrião do ideal da racionalidade moderna em conjunto com o positivismo, assim como pensa David Harvey, que entende que o século XVIII é o marco histórico de fortalecimento da modernidade.

Neste sentido, Boaventura de Sousa Santos em seu livro A crítica da razão indolente: contra o desperdício da experiência diz que a partir dos séculos XVI e XVII a modernidade ocidental emergiu como um ambicioso e revolucionário paradigma sociocultural assentado numa tendência dinâmica entre regulação social e emancipação social, ou seja, mesmo antes do século XVIII já se fundavam as bases do ideal racional moderno.

Embora não tenha feito parte do nosso quadro de leituras específicas, é oportuno destacar a sua contribuição nos debates sobre modernidade e pós-modernidade que é elaborada por Jean-François Lyotard. Este é citado por Anthony Giddens, Boaventura de Sousa Santos e David Harvey como responsável pela popularização do conceito de modernos e pós-moderno. Para ele a atividade científica era vista como autorreferente e autorrenovadora pelo pensamento moderno, sendo esta atividade nobre, pois tinha a função de romper com o "mundo das trevas" e contribuir para o desenvolvimento moral e intelectual do homem.

Já para Anthony Giddens, a "modernidade refere-se a estilo, costume de vida ou organização social que emergiram na Europa a partir do século XVII e que ulteriormente se tornaram mais ou menos mundiais em sua influência" (GIDDENS, 1991, p. 8). Ele destaca que houve uma descontinuidade da modernidade com a ordem social tradicional a partir de três pontos fundamentais: o primeiro seria o ritmo de mudança, que foi possível devido à rapidez com que os processos tecnológicos aconteciam; o segundo é escopo da mudança por meio das ondas de transformações sociais; e o terceiro pela natureza intrínseca das instituições modernas que são o estado-nação, o nacionalismo e a democracia.

Anthony Giddens é bem mais otimista do que Boaventura de Sousa Santos quanto à perspectiva de um ideal racional moderno que possibilitou, entre outras mudanças significativas, uma soberania que deu autonomia nas relações dos estados, como podemos destacar na escrita deste ao dizer que “(...) a soberania do estado moderno foi desde o início dependente das relações entre estados, em termos das quais cada estado reconhecia a autonomia dos outros dentro de suas fronteiras" (GIDDENS, 1991, p. 63). Porém, é 
necessário pontuar que a modernidade não possibilitou de fato essa soberania entre os povos e muito menos a autonomia e o respeito de suas fronteiras, basta olharmos para os países colonizadores que exploraram as américas no inicio do período dito moderno e dos neocolonizadores que ocorreu na contemporaneidade com a exploração dos estados africanos.

Neste contexto podemos citar o pensamento de Marcelo Neves que interpretou o conceito de "modernidade periférica" e que segundo Alexandre Douglas Zaidan de Carvalho: "Neves relaciona a distinção entre centro de periferia aos processos coloniais, neocoloniais e pós-coloniais de que resultaram a exclusão massiva na periferia e enriquecimento do centro" (CARVALHO, 2020, p. 29). Deste modo, o ideal racional moderno possibilitou que houvesse uma exploração por parte do centro em detrimento da periferia e que é deste centro colonizador e neocolonizador que "se exportaram os ideais constitucionais de liberdade e igualdade" (CARVALHO, 2020, p. 29) tão caros à modernidade.

Ainda falando da abordagem de Giddens sobre a modernidade, ele diz que sua marca é a de uma reflexividade indiscriminada que, em alguns casos, é emancipatória e, em outros, opressiva. Este é um ponto de concordância com o pensamento de Giddens e que junto com a ideia que o mesmo disserta que ao invés de estarmos ingressando num período de pósmodernidade, estaríamos alcançando um período em que as consequências da modernidade estão se tornando mais radicalizadas e universalizadas, aproxima-o, de algum modo, do pensamento de Boaventura de Sousa Santos que mostrará que a emancipação não obteve êxito, destarte, entendemos que o ideal racional moderno ainda não foi superado na sua proposta.

O positivismo, a partir do século XIX, potencializou a regulação da ciência como um todo e, através do positivismo jurídico, regulou as ciências jurídicas, agindo como imunizador da racionalidade contra a contaminação de qualquer irracionalidade não capitalista, quer ela fosse Deus, a religião, a tradição, a metafísica, a ética, as utopias e os ideais emancipatórios. É justamente neste período que há uma convergência do paradigma da modernidade com o capitalismo e que segundo Boaventura de Sousa Santos é dividida em capitalismo liberal, capitalismo organizado e capitalismo desorganizado, fazendo com que a regulação se sobreponha a emancipação. 
Esta questão é um ponto fundamental no debate que Boaventura traz. Para este a modernidade se funda a partir de dois conhecimentos distintos que é justamente o conhecimento-regulação (no qual o ponto do saber se designa por ordem) e o conhecimentoemancipação (no qual o ponto do saber se designa por solidariedade). Essas duas formas de conhecimento se fundaram na matriz do ideal racional moderno eurocêntrico e, devido à forma como a ciência moderna se desenhou, levou a um conhecimento hegemônico regulador.

A absorção da emancipação pela regulação se desenvolve por meio dos princípios do Estado, da comunidade e do mercado, porém este desenvolvimento não ocorre de forma harmônica já que o princípio do mercado sobrepõe-se aos demais. As cidades tem um papel fundamental, pois foi "com a expansão das cidades comerciais e o aparecimento de novas cidades industriais no período do capitalismo liberal" (SANTOS, 2011, p. 56) que foi possível o desenvolvimento do princípio do mercado de forma global.

Neste contexto, o direito tem haver com esse processo hegemônico da regulação sobre a emancipação, pois o direito é "um mosaico de retórica, violência e burocracia" (SANTOS, 2013, p 26) e isto é feito porque o direito opera a partir de procedimentos regularizadores e padrões normativos. Ainda nesta perspectiva:

[...] a crise do paradigma da modernidade tem no jurídico um dado fundamental, pois teria sido um componente estratégico no processo perverso e fracassado de solução das contradições do projeto moderno, no qual a regulação sobrepôs-se à emancipação. (SANTOS, 2013, p. 26)

Um exemplo disso é a Declaração dos Direitos do Homem e do Cidadão, de 1789, da Revolução Francesa, que é um momento do ápice histórico-jurídico do pensamento racional moderno iluminista, com sua promessa de liberdade, igualdade e fraternidade. Com esta declaração o direito foi levado a uma condição de "seu caráter emancipatório (vencer a tirania) e sua função regulatória (a juridificação do social e do político pelo poder estatal)" (SANTOS, 2013, p. 27).

Grandes promessas da modernidade permanecem sem ser cumpridas ou, se foram, tiveram efeitos perversos. Entre essas promessas estão as de igualdade social entre os povos o que não ocorreu, pois mais pessoas morreram de fome no século passado do que em qualquer outro século, até mais do que no período da peste negra. Outra promessa que não foi cumprida 
é a da liberdade, pois muitos países sequer vivem numa liberdade democrática plena. E por fim a promessa de fraternidade, mas o que ocorreu foi à tendência de uma banalização do próprio ser no mundo, uma "banalidade do mal", como aponta Hannah Arendt (1999) ao interpretar o fenômeno dos campos de concentração como frutos da modernidade. Ou seja, tivemos um fracasso de políticas que prometiam desenvolvimento e progresso, mas na verdade promoviam e promovem a destruição de culturas locais, por isso Boaventura se posiciona como pensador pós-moderno.

Deste modo, David Harvey também se coloca como pensador pós-moderno, pois “a única coisa segura na modernidade é a insegurança, e até a sua inclinação para o caos totalizante" (HARVEY, 1992, p. 22). Embora a promessa do ideal racional moderno fosse o progresso e o acúmulo de conhecimento em busca da emancipação humana, o que houve, a partir do século XX, "com seus campos de concentração e esquadrões de morte, seu militarismo e duas guerras mundiais, sua ameaça de aniquilação nuclear e sua experiência de Hiroshima e Nagasaki” (HARVEY, 1992, p. 23), foi o afastamento demasiado do otimismo de um mundo melhor proposto pela modernidade.

A partir disto podemos pensar e falar da tradição da teoria crítica da modernidade, que tem o intuito de criar um novo senso da realidade que seja emancipatório, pois o ideal racional moderno é um paradigma dominante. Por isso, a teoria crítica da modernidade pensa, a partir da crise da modernidade, a ideia da transição paradigmática que seria o que Boaventura chama de "crítica da razão indolente". Temos que pensar a modernidade, a partir dessa concepção crítica no sentido de apontar alternativas para a sociedade e isto não quer dizer "prever o futuro", mas pensar utopias que só se realizarão no futuro e não apenas na análise do que existe. Ou seja, quando se aponta alternativas para a sociedade se faz um conhecimento-emancipação que tem três pilares de confrontação com o ideal racional moderno: monoculturalismo $\mathrm{x}$ interculturalismo; peritagem científica heroica ao conhecimento edificante; da ação conformista à ação rebelde.

Neste contexto a modernidade é dominante por ter passado por um processo de construção cultural do ocidente que pretende ser global e “[...] sendo um modelo global, a nova racionalidade científica é também um modelo totalitário" (SANTOS, 2011, p. 61). Porém, é oportuno delimitar que a construção cultural do ocidente não se trata de paradigma 
universal e global por si só, mas sim um paradigma local que se tornou global com êxito através de um localismo globalizado. Para Boaventura este localismo globalizado:

\footnotetext{
Consiste no processo pelo qual determinado fenômeno local é globalizado com sucesso, seja a atividade mundial das multinacionais, a transformação da língua inglesa em língua franca, a globalização do fast food americano ou da sua música popular, ou a adoção mundial das leis de propriedade intelectual ou de telecomunicações dos EUA. (SANTOS, 1997, p. 16)
}

Outra questão que é oportuno destacar a partir de dois elementos do ideal racional moderno: o primeiro é a questão da evolução da ciência, pois esta foi sendo valorizada, no sentido do homem ter o controle (regulação) da natureza para melhor explorá-la e racionalizar o seu uso para produzir bens materiais para suprir as necessidades humanas; um segundo elemento é o conhecimento racional da sociedade que poderia organizar racionalmente a mesma como modo de articulação social que garantisse autonomia e liberdade aos seres sociais através da emancipação. Essas duas questões unificavam a dimensão do ideal racional moderno e em face disso os pós-modernos estabeleceram uma crítica à modernidade, pois basta olhar como se encontra a situação da natureza e a emancipação das pessoas.

Entrando no debate sobre a pós-modernidade, que no nosso entendimento é uma pluralidade de espaços e temporalidades heterogêneos baseada na multiplicidade de culturas e discursos, de várias pequenas narrativas, do relativismo da moral absoluto. Assim, a proposta da pós-modernidade é que o princípio da coexistência possa substituir o princípio da universalização e a liberdade, a igualdade e a fraternidade, que fizeram o grito de guerra da modernidade, passam a ser a liberdade, a diversidade e a tolerância à constituição da fórmula da pós-modernidade. Ou seja, a pós-modernidade acena para uma nova sensibilidade, que traz à tona a consciência da pluralidade e da diferença.

Neste sentido, André Copetti citando Nietzsche e Warat mostra que a leitura destes deixou uma angústia que "diz respeito à igualdade" considerando-a "um dos elementos funcionalizadores centrais da política e do Direito modernos”. A concepção de igualdade oriunda do ideal racional moderno se encontra atrelada à ideia de universalidade, embora isto pudesse não estar da fundação da modernidade, passa-se ao logo do tempo a cultura hegemônica de um paradigma homogeneizador de unidade funcional da modernidade. Para André Copetti, essa unidade "não é adequada para a abordagem e o tratamento hermenêutico 
dos direitos, cuja tutela demande o reconhecimento da diferença em sua multiplicidade caleidoscópica, a que podemos nominar como diversidade" (LUCAS; SANTOS, 2016, p. 174).

\section{O SURGIMENTO DA CIDADE COMO IMPULSIONADOR DO IDEAL RACIONAL MODERNO}

Sobre a cidade como uma "invenção" da modernidade, Giddens aponta que esta é apenas continuidade ilusória da pré-modernidade, pois "os modernos assentamentos urbanos frequentemente incorporam os locais das cidades tradicionais, e isto faz parecer que meramente expandiram-se a partir delas" (GIDDENS, 1991, p. 12). Neste sentido, os espaços urbanos surgidos a partir da modernidade tem um traço do ideal racional moderno, pois se expandiram a partir destes princípios de organização e ocupação dos espaços urbanos com o intuito de promover essa nova ordem baseada na cientificidade e na razão.

Henri Lefebvre foi quem inaugurou os estudos sobre o direito à cidade na década de 1960 e um dos pontos principais da obra deste é a análise crítica que é feita do "projeto de modernização que (e)levou Paris do patamar de cidade medieval ao de cidade da luz ou capital da modernidade" (BELLO, 2019, p. 233).

Para Lefebvre (2001) a "problemática urbana" tem um ponto de partida fundamental que é o processo de industrialização e este processo "caracteriza a sociedade moderna", embora "a Cidade preexista à industrialização", ou seja, a urbanização existe mesmo antes do ideal racional moderno, como podemos destacar: a cidade oriental; a cidade arcaica; e depois a cidade medieval. Tanto Henri Lefebvre quanto Boaventura de Sousa Santos entendem que a expansão do modelo de cidade que temos hoje é fruto da industrialização. Para o primeiro, a cidade "tem uma poderosa realidade" na industrialização que nasce do "capitalismo concorrencial" (Lefebvre, 2001, p. 12) e para o segundo a industrialização promoveu a “expansão das cidades comerciais" e o "aparecimento de novas cidades indústrias" e isto ocorre no primeiro período do capitalismo que é o capitalismo liberal (SANTOS, 2011, p. 145). Ainda neste contexto Daniel Mendes Mesquita de Sousa destaca que "a industrialização pressupõe a ruptura do sistema urbano preexistente, ou seja, implica na destruição das estruturas" (SOUSA, 2019, p. 108). 
Se para Boaventura o capitalismo é fruto do ideal racional moderno e ele fortalece a regulação em detrimento da emancipação, podemos dizer que a cidade moderna é o espaço onde ocorre esta regulação que tem o intuído de unificar, universalizar, globalizar e convergir o paradigma da modernidade com o capitalismo, pois o ideal racional moderno é um paradigma dominante. Como destacamos acima, esse ideal racional tem duas premissas que se complementam: uma é a de que o homem deve ter o controle (regulação) da natureza para melhor explorá-la e racionalizar o seu uso para produzir bens materiais para suprir as necessidades humanas, e a outra é conhecimento racional da sociedade que poderia organizarse racionalmente, e estas premissas ocorrem nas cidades.

Portanto, para Lefebvre são essas as raízes históricas do direito à cidade que fazem com que o urbano seja o "centro do poder" e "este período traz uma nova racionalidade" (LEFEBVRE, 2001). Esta "nova racionalidade" toma forma organizada nos séculos XIX e XX (SOUSA, 2019) e é neste período que Boaventura chama de capitalismo organizado que "no campo jurídico (...) se redefiniram o cientificismo e o estatismo do direito" (SANTOS, 2011, p. 145).

Eulalia Portela Negrelos, ao analisar as tendências históricas no âmbito territorial, em particular no urbano, aponta dois fortes pontos sobre isto. O primeiro é "a teoria sobre a cidade do capital" e o segundo é a cidade como foco da globalização e da "reforma social modernizadora (como discurso técnico)" (NEGRELOS, 2009, p. 548). O primeiro se encontra alinhado com o pensamento de Lefebvre quanto ao pensamento de uma análise crítica da cidade, sendo esta o meio de reprodução do capital e espaço de segregação social em que alguns locais centrais são valorizados em detrimento de outros "expulsando os pobres das áreas centrais para que isto se realizasse" (SOUSA, 2019, p. 109). O segundo ponto que focaliza a cidade como meio da globalização e do discurso técnico modernizador que se inicia no final do século XIX e se exacerba no século XX com sua face de exploração da cidade promovendo uma "elitização e expulsão das camadas populares daqueles territórios que se convertem em interessantes para o capital imobiliário ou produtivo" (NEGRELOS, 2009, p. 549).

Michel de Certeau ao discorrer sobre a cidade como espaço de sociabilidade mostrando que é nela que as pessoas moram, crescem, respiram, trabalham, se divertem, praticam suas atividades cotidianas e culturais, formula um conceito sobre a cidade a partir de 
uma "racionalidade urbanística". Este conceito é definido "pela possibilidade de uma tríplice operação": a produção de um "espaço próprio" organizado racionalmente; um "não tempo" que viabilize através de "estratégias científicas unívocas" a substituição às resistências que ainda tentam operar as alternativas da tradição; e por fim, "a criação de um sujeito universal e anônimo que é a própria cidade" (CERTEAU, 2014, p. 160).

Como podemos observar o conceito de cidade elaborado por Certeau tem fundamento no pilar da modernidade que tem nesta as ideias de organização racional, um sujeito universal e uma cientificidade unívoca, sendo a cidade a maquinaria e o espaço das práticas da modernidade. Este espaço em muitos momentos se mistura entre o privado e o público na vida cotidiana.

Neste contexto, da cidade como espaço que se mistura o público e o privado, Nelson Saldanha faz uma analogia da praça como local público e o jardim como local privado. Estes têm diversas formas, origens e sentidos. Ele também aborda a ideia de espaço na concepção histórica, bem como seus usos e a utilização do tempo nestes espaços. Entre estes espaços inclui-se a vida urbana e esta passa por uma crise devido às alternâncias entre o uso público e privado destes espaços, pois "as estruturas urbanas desencadearam ou ocasionaram as grandes crises, inclusive porque nelas se exacerbaram e se alteraram as próprias diferenças entre privacidade e publicidade" (SALDANHA, 1983, p. 107).

Deste modo, as crises que se arrastam na modernidade vem a ser crises da tensão entre a vida privada e a vida pública e que isto ocorre no seio das cidades. Mas esta crise não é só da modernidade, pois já se fazia parte entre os clássicos de Roma e da Grécia em especial da dimensão da compreensão política da concepção pública. Para Saldanha, o moderno se inicia com as grandes revoluções, em especial o Renascimento que entre as suas imagens tem-se a das "grandes casas senhoris" ainda herdadas do medievo.

Este tipo de casa, que correspondeu ao absolutismo europeu (dentro do qual existiu um específico sentido de espaço e de grandeza espacial), este tipo de casa aparece na pintura dos séculos XVII a XIX, tanto nos ambientes rurais - aquele ambiente inconfundível do Mou/in de Ponto/se de Corot - quanto nos urbanos. (SALDANHA, 1983, p. 108) 
No caso das casas urbanas, existia como proposta, mostrar o poder dos "senhores" que começam a ser exercidos no âmbito das cidades. Uma amostra disso são os grandes jardins que existiam nessas casas, também como forma de mostrar o poder "senhorial" e estes muitas vezes se confundiam com o espaço público e por isto Saldanha fala desta crise do moderno.

O ideal racional do pensamento moderno e a relação do intelectual moderno com suas funções e relações com a modernidade é tratada por Saldanha a partir das utopias. Sobre isto, ele aborda que estas surgem como expressão da exaltação de uma mentalidade que sobrepõe o público ao privado. Ou seja, o pensamento utópico é concebido por meio das experiências vivenciadas nas praças e da sua relação de artificialidade que existe nas utopias.

A partir do século XIX esta mentalidade que sobrepõe o público ao privado é o ponto central que demarca a diferença histórica entre a antiguidade e a modernidade e tudo isso se consolida ainda mais com o pensamento liberal.

O advento do liberalismo, no mundo chamado ocidental, consagrou correlativamente o racionalismo burguês e a secularização da cultura, preparando quase paradoxalmente (em relação ao individualismo) a tecnocracia e os regimes de massa que eclodiriam em nosso século - em conexão com os pavorosos aumentos demográficos, que são a causa maior disto tudo. (...) Com a massificação, veio também a sobrecarga de gente nos lugares (Ortega observou isto na Rebelião). (SALDANHA, 1983, p. 111)

Esta sobrecarga de gente que foi permitida devido à massificação só vem a reforçar o que já dissemos acima, que a cidade que temos e conhecemos hoje é fruto do ideal racional moderno. Em consonância a isto, podemos dizer que com o Estado Moderno em sua fase liberal "é que se passou a haver constituições propriamente ditas", pois no medievo, que para Saldanha é a época do privatismo, "não teria havido constituições, mas apenas cartas". Portanto, com a instituição de constituições propriamente ditas é que se tem "destacado com plenitude a dimensão pública do indivíduo" e "as revoluções burguesas entronizaram a praça como lugar de decisões históricas" (SALDANHA, 1983, p. 116).

Destarte, o ideal racional moderno que tem no indivíduo uma dimensão pública e não mais privada como era no medievo, traz a concepção do indivíduo público, sobretudo, no seio nuclearmente urbano. Neste sentido, Saldanha destaca, que "com a renovação da experiência urbana, retomada a partir dos séculos XVI e XVII e de uns tempos para cá tornada mundial e 
intensiva, a categoria público veio sendo crescentemente reestimada" (SALDANHA, 1983, p. 116). Portanto, é necessário entendermos que o advento histórico da burguesia, do capitalismo e do liberalismo tem seu fundamento no ideal racional moderno, assim como a cultura urbana também tem.

\section{O DIREITO À CIDADE PARA ALÉM DO IDEAL RACIONAL MODERNO}

Como podemos observar o surgimento da cidade como impulsionador do ideal racional moderno se fortalece a partir da cidade do capital e do foco da cidade como elemento da globalização e da reforma social modernizadora. Ou seja, o modelo de urbanismo que se instala é o da reprodução do capital e espaço de segregação social em que alguns locais centrais são valorizados em detrimento de outros. Isto se inicia no final do século XIX e se exacerba no século XX com sua face de exploração da cidade promovendo uma elitização e expulsão das camadas populares daqueles territórios que se convertem em interessantes para o capital imobiliário ou produtivo.

Esse modelo de urbanismo se espalha pelo mundo e assim como o ideal racional moderno, as cidades passam e a ter um sentido homogêneo, universal, globalizado e que contribui para a convergência do paradigma da modernidade com o capitalismo e que tem no direito o seu mecanismo de regulação. Se para Marcelo Neves existe a "modernidade periférica", podemos dizer que no campo do direito à cidade existe a cidade periférica e que se funda dentro do ideal racional moderno que prometeu uma sociedade justa, fraterna e igual, mas o que vimos ao longo do tempo foram as cidades ficarem cada vez mais excludentes e que as oportunidades para as pessoas que nelas vivem não ocorrem de forma igualitária.

Neste sentido, é oportuno pensarmos o direito à cidade para além do ideal racional moderno e que esta concepção da cidade do pensamento único seja desmanchada, pois entendemos que o direito à cidade se insere no chamado direito coletivo, sendo este direito exercido pelos "habitantes das cidades, especialmente dos grupos vulneráveis e desfavorecidos" (BELLO, 209, p. 241) devendo ser garantido os seus "usos e costumes" (CERTEAU, 2014) de forma a alcançar o pleno exercício das cidades "como um bem comum de todos" (SAULE JUNIOR, 2016, p. 75).

No tocante às questões urbanas, David Harvey se afasta de uma ideia modernista do direito à cidade, pois esta se baseia numa tecnologia racional e eficiente sustentada no 
planejamento urbano que se pretende ser unívoco e universal. Por ser um pensador pósmoderno, David Harvey conceitua o "tecido urbano como necessariamente fragmentado" (HARVEY, 1992, p. 69), ou seja, o planejamento urbano deve ter uma concepção independente e autônoma sem precisar ser moldada a um padrão estético específico.

Entendemos ser pertinente apontar algumas questões para que possam ser pensadas a partir do direito à cidade, pois é predominantemente no urbano que as pessoas vivem hoje. $\mathrm{O}$ primeiro ponto é a partir do pensamento de Henri Lefebvre que: entende que a sociedade urbana começa sobre os escombros da cidade antiga; o direito à cidade deve ser encarado como um direito a vida urbana; nenhum órgão, seja ele do estado ou não, seja ele científico ou não, podem fornecer um modelo de urbanização pronto e acabado que forneça todos os elementos do direito à cidade; não existe uma cidade ideal, mas cada uma tem suas peculiaridades, necessidades; cada tipo urbano tem uma centralidade específica.

O segundo ponto, para finalizar, é no sentido de "des-pensar", proposto por Boaventura de Sousa Santos, e neste sentido entendemos que o direito à cidade deve-se atentar a uma cidadania que não faça da sua regulação um empecilho à sua emancipação. A cidade tem que ser "des-pensada" para que se abra para uma reconstrução descontínua e não arbitraria que "dá origem a novos perigos, riscos e inseguranças, mas que também aumentam as oportunidades para a inovação, a criatividade e a opção moral” (SANTOS, 2011, p. 186). Toda essa problemática epistemológica deve perpassar pelo conhecimento local e pelas experiências de vida que cada um e cada uma vivenciam nas cidades.

\section{CONSIDERAÇÕES FINAIS}

Foi possível mostrar com este artigo que, embora as cidades já existissem mesmo nas civilizações mais antigas, foi com o advento da modernidade que elas se expandem e são as molas propulsoras do ideal racional moderno. Este ideal tem como fundamento a racionalidade, a globalização, a regulação e o fomento do capitalismo e foi por meio das cidades que esses dias foram possíveis de se fundar como concepção de um mundo homogêneo.

No final deste artigo foi destacado e apontando para a possibilidade de repensarmos a forma que as cidades foram se constituindo e que o direito à cidade deve ser o responsável pelo pensamento de cidades para além do ideal racional moderno. Portanto, este artigo tem 
sua contribuição fundamental nos estudos sobre a modernidade, o ideal racional e o direito à cidade.

\section{Referência bibliográfica}

ARENDT, Hannah. Eichmmam em Jerusalém. Tradução de José Rubens Siqueira. São Paulo: Companhia das Letras, 1999.

BELLO, Enzo; RIBEIRO, Mariana Dias. O Direito à Cidade e os Novos Direitos Urbanos como Direitos Humanos e Direitos Fundamentais. In: BELLO, Enzo; KELLER, Rene José. (Orgs.) Curso de direito à cidade: teoria e prática. 2. Ed. Rio de Janeiro: Lumem Juris, 2019.

CARVALHO, Alexandre Douglas Zaidan de. O constitucionalismo visto da periferia: um olhar sobre a contribuição de Marcelo Neves. In: TEIXEIRA, João Paulo Allain. LIZIERO (Orgs.) Direito e sociedade - Volume 1: Marcelo Neves como intérprete da modernidade periférica. Andradina: Meraki, 2020.

CERTEAU, Michel de. A invenção do cotidiano: a arte de fazer. Tradução de Ephraim Ferreira Alves. 22. Ed. Petrópolis: Editora vozes, 2014.

ERRARA, Ricardo Czepurnyj. Uma crítica da concepção do medievo como tempo de trevas e produções medievais. Revista de Pós-graduação Multidisciplinar, [S.1.], v. 1, n. 3, p. 307318, mar. 2018. I Disponível em http://www.fics.edu.br/index.php/rpgm/article/view/717. Acesso em 14 de agosto de 2020.

GIDDENS, Anthony. As consequências da modernidade. Tradução de Raul Fiker. São Paulo: Editora UNESP, 1991.

GROSSI, Paolo. Da sociedade de sociedades à insularidade do estado entre medievo e idade moderna. Revista Sequência, Florianópolis, p. 9-28, jan. 2007. Disponível em https://periodicos.ufsc.br/index.php/sequencia/article/view/15042/13714. Acessado em 27 de maio de 2020.

HARVEY, David. Condição pós-moderna: uma pesquisa sobre as origens e da mudança cultural. Tradução de Adail Ubirajara Sobral e Maria Stela Gonçalves. São Paulo: Edições Loyola, 1992. 
LEFEBVRE, Henri. O direito à cidade. Tradução de Rubens Eduardo Frias. São Paulo: Centauro, 2011.

LUCAS, Doglas Cesar; SANTOS, André Leonardo Copetti. O direito à diferença e a proteção jurídica das minorias na América Latina. Revista Direito Em Debate, Ijuí, v. 25, n. 45, pp. 172-208, jan/jun 2016. Disponível em: https://doi.org/10.21527/2176-6622.2016.45.172-208. Acessado em 27 de maio de 2020.

NEGRELOS, Eulalia Portela. Avaliação de novos projetos urbanos metropolitanos. Limites do ente federativo municipal. Cadernos Metrópole. São Paulo, v. 11, n. 22, pp. 545-570, jul/dez 2009. Disponível em: https://doi.org/10.5335/hdtv.15n.1.5279. Acessado em 27 de maio de 2020.

PESAVENTO, Sandra Jatahy. História e história cultural. Belo Horizonte: Autêntica, 2008.

SALDANHA, Nelson. O jardim e a praça: ensaio sobre o lado "privado" e o lado "público" da vida social e histórica. Recife: Fundação Joaquim Nabuco, 1983.

SAULE JUNIOR, Nelson. O direito à cidade como centro da nova agenda urbana. IPEA Boletim regional, urbano e ambiental. São Paulo, n. 15, jul/dez 2016. Disponível em: http://repositorio.ipea.gov.br/handle/11058/7114?locale=es Acessado em 27 de maio de 2020.

SANTOS, Boaventura de Sousa. A crítica da razão indolente: contra o desperdício da experiência. 8. Ed. São Paulo: Editora Cortez, 2011.

Por uma concepção multicultural de direitos humanos. Revista Crítica de Ciências Sociais. Coimbra, n. 48, pp. 11-32, jun. 1997.

Direitos humanos, democracia e desenvolvimento. São Paulo: Editora

Cortez, 2013.

SOUSA, Daniel Mendes Mesquita de. Arquitetura e Urbanismo: Raízes Urbanas do Direito à Cidade e suas Possibilidades no Presente. In: BELLO, Enzo; KELLER, Rene José. (Orgs.) Curso de direito à cidade: teoria e prática. 2. Ed. Rio de Janeiro: Lumem Juris, 2019. 